\title{
Individual growth analysis of the Pacific yellowlegs shrimp Penaeus californiensis via multi-criteria approach
}

\author{
José A. Félix-Ortiz ${ }^{1}$, E. Alberto Aragón-Noriega², Nicolás Castañeda-Lomas ${ }^{1}$ \\ Guillermo Rodríguez-Domínguez ${ }^{1}$, Wenceslao Valenzuela-Quiñónez ${ }^{3}$ \& Sergio Castillo-Vargasmachuca ${ }^{4}$ \\ ${ }^{1}$ Facultad de Ciencias del Mar, Universidad Autónoma de Sinaloa, Mazatlán, Sinaloa, México \\ ${ }^{2}$ Unidad Guaymas, Centro de Investigaciones Biológicas del Noroeste, Guaymas, Sonora, México \\ ${ }^{3}$ Instituto Politécnico Nacional-CIIDIR, Unidad Sinaloa, Departamento de Acuacultura \\ Guasave, Sinaloa, México \\ ${ }^{4}$ Posgrado en Ciencias Biológico Agropecuarias, Universidad Autónoma de Nayarit \\ Nayarit, México \\ Corresponding author: E. Alberto Aragón-Noriega (aaragon04@ cibnor.mx)
}

\begin{abstract}
Length-frequency data of juveniles and sub-adults of Penaeus californiensis were analyzed, collected from January 2002 to January 2003 in the Agiabampo lagoon system and adjacent marine coastal zone. Six models were parameterized with four criteria, in addition to a mixed criterion (fat-tail and depensatory), to estimate the parameters that best fit the growth curve. The model that best fit was the Johnson model with the mixed criterion in females and males: $k=6.02(5.93-6.12) ; L_{\infty}=188.8(186.3-191.8) ; t_{0}=0.0221(0.0207$ $0.0234)$; and: $k=8.98(8.85-9.12) ; L_{\infty}=153.3(151.7-155.0) ; t_{0}=0.0386(0.0378-0.0394)$, respectively. The conclusion is that: 1) the mixture approach found in this study as best leads to the application of a very highperformance objective function to analyze individual length-at-age variability, 2) shows that the best model to describe the growth trajectory of $P$. californiensis in marine and estuarine environments is a sigmoid curve with an inflection point near to cero age (Johnson model).
\end{abstract}

Keywords: Penaeus californiensis; growth curve; length-frequency; multimodel; multi-criteria; Gulf of California

\section{INTRODUCTION}

The estimation of individual growth is one of the important objectives for evaluating and managing fisheries resources. Many environmental processes that species must face in their habitats are revealed in the way they grow. The shrimps' species of the family Penaeidae are short-lived, marine organisms with different habitats throughout their life history; it becomes a problem when individual growth is being fitted throughout its entire life cycle. Some studies estimated the growth parameters of Penaeus californiensis in its adult stages, captured by the offshore fishing fleet (Chávez \& Rodríguez, 1971; Galicia, 1976; López et al., 2003). Dall et al. (1990) assumed a hypothesis based on shrimp growth in two habitats of their life cycle; in the estuarine system, the growth rates are linear, since all the energies are being assigned to the somatic growth. While in the marine zone, shrimps become mature when the energy is diverted towards the reproduction and, therefore, the somatic growth decreases. Studies dedicated to estimating the growth in two habitats for penaeids shrimps are scarce. Montgomery et al. (2010) described the growth of an Australian metapenaeid in two adjacent estuaries and ocean zones, and Monsreal et al. (2016) described juveniles' growth of two penaeid species in the Gulf of Mexico. Rivera-Velázquez et al. (2010) examined the length-frequency distribution of $P$. vannamei in its estuarine stage. In other taxa, Ortega et al. (2016) estimated the growth of the crab Callinectes arcuatus, joining the estimated curves in cultured conditions with the estimated curves of commercial catches. Studies to determine age in invertebrates have had to concentrate on techniques that do not use hard parts; tagging and recapture of organisms, frequency

Corresponding editor: Patricio M. Arana 
distribution size analysis, rearing under laboratory conditions, and evaluating lipofuscin in tissues of organisms (Montgomery et al., 2010). One of the indirect methods, size-frequency distributions, is analyzed, identifying modes representing age groups or cohorts (Hilborn \& Walters, 1992). However, when the distributions are not poly-modal, the graphic interpretation is very subjective (Macdonald \& Pitcher, 1979). In short-lived species with well-defined reproductive periods, the size-frequency distributions provide reliable information about individual growth models, becoming the most convenient and economical method for analyzing the size-age structure in decapod crustaceans (Vogt, 2012).

The mathematical equations or models used to describe the growth in animals anticipate different shapes of curves; the most used is the growth model of Von Bertalanffy (1938) (VBGM), undoubtedly because it was introduced in fisheries assessment models. Nevertheless, this does not mean that it is best for any situation. Other alternative models have been used, such as Gompertz (1825), Johnson (1935), Richard (1959), Logistics (Ricker, 1975), and Schnute (1981). The latter incorporates VBGM, Gompertz, Richards, and Logistics as special cases. The previous models are characterized by having an asymptotic parameter. They can be of two forms; sigmoid or negative exponential (Aragón-Noriega, 2016). The sigmoid shape curve, Gompertz, Logistic, Richards, and Johnson type models are characterized by having an inflection point. The inverted exponential model is the VBGM, is fast growing in the early stages of life. There are generalized versatile models such as the Generalized von Bertalanffy GVB that have a parameter that shapes the curve before reaching the asymptotic age so that this model can be sigmoid or inverted exponential.

The models mentioned above have some unknown parameters that must be estimated. The critical question is how to calculate the parameters of the models. Traditionally, model parameterizations in not linear solutions have been done using the criterion of least square. Recently the maximum likelihood becomes the most used strategy to parametrize the models. New model parameterization approaches have been used and can be unconventionally called the "fat-tail", which consists of increasing the size of the tail of the density distribution so that the probability of occurrence of an event does not move away from the average (Chen \& Fournier, 1999). Also, another approach that consists in estimating the variance for each age "depensatory" variance increases with age (Restrepo et al., 2010; Luquin et al., 2016). On the contrary, when variance decreases with age, "compensatory" was developed by Aragón-Noriega et al. (2017) in Penaeus vannamei.
When one tries to fit more than one model, a goodness of fit criterion to decide which best describes the data must be established. Krüger (1969) found that the sole Eopsetta jordani was better represented by the model he developed that the VBGM. This comparison was performed using the percentage of differences of the observed data with the estimates as a test. Statistical criteria to select the best model describing the trajectory of the growth curve in a given situation, from a set of candidate models, uses the information theory. Zhu et al. (2009) compared six decision criteria and recommended the Akaike information criterion (AIC) and the Bayesian information criterion (BIC) as the best for the selection of growth models (Akaike, 1973; Burnham \& Anderson, 2002).

In summary, when a researcher tries to describe the growth of any species under given environmental conditions must decide among different possible anticipated curves, many parametrization strategies, and a bunch of goodness of fit tests to select the best trajectory of the curve. For those reasons, the objective of the present study was to estimate the growth of yellowlegs shrimp P. californiensis in the Agiabampo coastal lagoon and adjacent marine zone, using the multimodal technique with methods of conventional and non-conventional parametrization, also using a mixed approach of two unconventional methods, to select the model that best describes its growth. In other words, the objective was twofold, biological, and statistical.

\section{MATERIALS AND METHODS}

The Agiabampo coastal lagoon system is located on the continental side of the Gulf of California (26 $28^{\prime} 30^{\prime \prime}$ $\left.26^{\circ} 8^{\prime} 15^{\prime} \mathrm{N}, 109^{\circ} 18^{\prime} 24^{\prime}{ }^{\prime}-109^{\circ} 5^{\prime} 12^{\prime \prime} \mathrm{W}\right)$. It is composed of three separate bodies of water: Estero de Bacorehuis, Estero de Jitzamuri, and Estero de Bamocha. It has an extension of $184 \mathrm{~km}^{2}$; it communicates permanently with the sea through a channel of $1.5 \mathrm{~km}$ wide (Fig. 1). The annual evaporation is about $3000 \mathrm{~mm}$, to the annual precipitation of about $300 \mathrm{~mm}$ (Valenzuela et al., 2006).

\section{Data analysis}

The collection of the biological sample was carried out from January 2002 to January 2003, once a month for five consecutive days (full moon \pm 2 days) with sets made every $1.5 \mathrm{~h}$, which were made from small vessels $7 \mathrm{~m}$ long, equipped with nets of $15 \mathrm{~m}$ long and $32 \mathrm{~mm}$ mesh.

Caught shrimp were measured (total length, from the tip of the rostrum to the tip of telson) and subsequently grouped at intervals of $5 \mathrm{~mm}$ each gender sepa- 


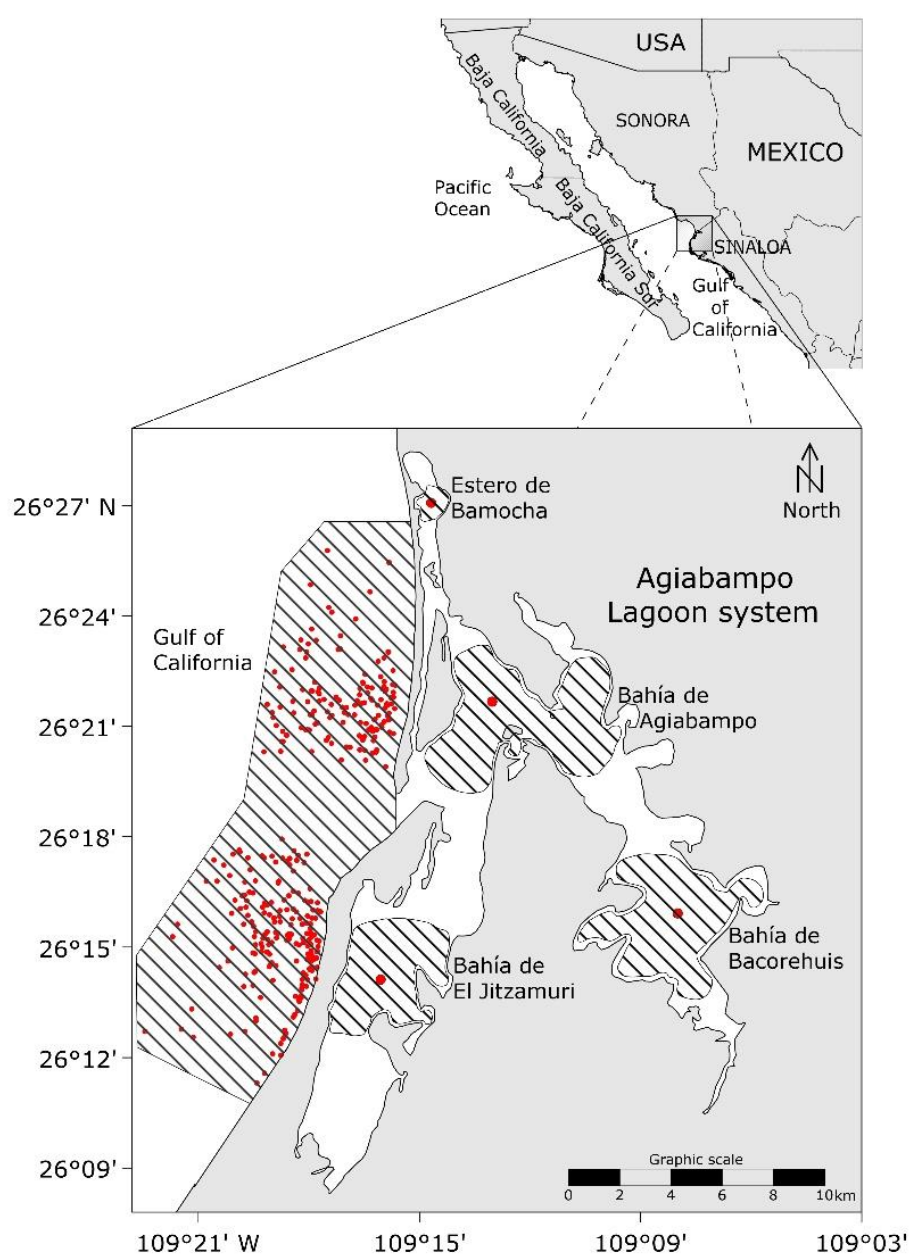

Figure 1. Location of the Agiabampo coastal lagoon and offshore adjacent area, Sinaloa-Sonora, Mexico. The pattern sites are the study areas; the dots represent the sites of greatest abundance.

rately. A multinomial model was used to identify the mean and standard deviation of each cohort with the equation:

$$
F_{i}=\sum_{a=1}^{n}\left[\frac{1}{\sigma_{a} \sqrt{2 \pi}} e^{\frac{\left(x_{i}-\mu_{a}\right)^{2}}{2 \sigma_{a}^{2}}}\right] * P_{a}
$$

where $x_{i}$ is the classmark for group $i, \mu_{a}$ is the average of the cohort $a, \sigma_{a}$ is the standard deviation of the cohort $a, P_{a}$ is the weight factor of the cohort $a$, and $F_{i}$ is the frequency of class mark for group $i$.

The model was adjusted by maximizing the following likelihood function:

$$
L L\left\{X \backslash \mu_{a}, \sigma_{a}, P_{a}\right\}=-\sum_{i=1}^{n} f i \operatorname{Ln}\left(\frac{F_{i}}{\sum F_{i}}\right) *\left(\sum f_{i}-\sum F_{i}\right)^{2}
$$

where $\left\{X \backslash \mu_{a}, \sigma_{a}, P_{a}\right\}$ is the objective to be maximized for the parameters $\mu_{a}, \sigma_{a}, P_{a} ; f i$ is the observed frequency of the classmark $i$, and $F_{i}$ is the estimated frequency for the class $i$ mark with the multinomial model.
The cohorts were defined according to the following criteria:

1) Mean separation index $\geq 2$ (Sparre \& Venema, 1998):

$$
\text { I.S. }=2 * \frac{\left(\mu_{2}-\mu_{1}\right)}{\left(\sigma_{1}+\sigma_{2}\right)}
$$

2) Akaike information criterion (AIC) (Burnhan \& Anderson, 2002). The smallest value of AIC corrected for small samples AICc was interpreted as the best fit:

$$
A I C_{c}=2(k-L L)+(2 k(k+1) /(n-k-1))
$$

where $k$ is the number of estimated parameters, $L L$ is the maximum likelihood value, and $n$ is the number of observations.

\section{Growth curves estimation}

Ever since the cohorts were identified, they were plotted by time sequence; this allowed us to identify the cohorts' modal progression. It was possible to generate alternative hypotheses concerning the exact modal 
progression (Montgomery et al., 2010; RodríguezDomínguez et al., 2012). The initial size of $12 \mathrm{~mm}$ at 30 days was considered, annualized 30/365 (AragónNoriega \& Calderón-Aguilera, 2001). As relative age sizes were obtained, six growth models were used; von Bertalanffy (VBGM), a generalized model of von Bertalanffy (GVB), Logistics, Gompertz, Johnson and Richards, which formulas of are described as follow:

VBGM: $\quad L_{t}=L_{\infty}\left(1-e^{-k\left(t-t_{0}\right)}\right)$

GVB: $\quad L_{t}=L_{\infty}\left(1-e^{-k\left(t-t_{0}\right)}\right)^{D}$

Logistic: $\quad L_{t}=L_{\infty}\left(1+e^{-k\left(t-t_{1}\right)}\right)^{-1}$

Gompertz: $\quad L_{t}=L_{\infty} e^{\left(-e^{-k\left(t-t_{1}\right)}\right)}$

Johnson: $\quad L_{t}=L_{\infty} e^{-\frac{1}{k}\left(t-t_{0}\right)}$

Richards: $\quad L_{t}=L_{\infty}\left(1+\frac{1}{A} e^{-k\left(t-t_{0}\right)}\right)^{-D}$

For all these models, the evaluated parameters are described as $L_{t}$ : length at age $t, t:$ age, $L_{\infty}$ : average length of a very old organism (asymptotic length), $k$ : represents the coefficient of growth, $t_{0}$ : hypothetical age at which the length of the organism is zero, $t_{l}$ : inflection point of the sigmoid curve, $A$ and $D$ : These are dimensional parameters that shape the curve path.

Four residual criteria were considered to estimate the parameters of each model; conventional, "fattailed", depensatory, and compensatory, also a mixed method of two unconventional models.

\section{Conventional method}

Model parameters were obtained through iterations using the Excel ${ }^{\mathrm{TM}}$ computational package. The maximum likelihood criterion was used to fit the model with Newton's algorithm (Haddon, 2001). Only additive type error was considered. The maximum likelihood equation used as the target function was:

$$
L L(\theta \mid \text { datos })=-\left(\frac{n}{2}\right)(\ln (2 \pi)+2 * \ln (\sigma)+1)
$$

where $\theta$ represents the parameters of each model, and $\sigma$ represents the standard deviation of the errors that were calculated with the following equation:

$$
\sigma=\sqrt{\frac{1}{n} \sum\left(L t_{\text {observed }}-L t_{\text {estimated }}\right)^{2}}
$$

\section{Unconventional methods}

\section{"Fat tail" method (Chen \& Fournier, 1999)}

The maximum likelihood strategy was used to fit the models:

$$
L L(\emptyset \mid \text { datos })=\sum \ln \left\{\frac{1-p}{\sigma \sqrt{2 \pi}} e^{\left[-\frac{(T L-T L)^{2}}{2 \sigma^{2}}\right]}+\frac{2 p}{g \sigma \sqrt{\pi}}\left[1+\frac{(T L-\widehat{T L})^{4}}{(g \sigma)^{4}}\right]^{-1}\right\}
$$

where $\Phi$ represents each model's parameters, $\sigma$ the standard deviation of the errors, $g$ parameter of "thickness" of the distribution tail, $T L$ is the observed size, $\widehat{T L}$ the estimated size by the model, and $p$ the proportion of erroneous data.

\section{Depensatory method (Restrepo et al., 2010).}

The criterion of maximizing the likelihood function of the following equation was used to parametrize the models:

$$
L L(\varnothing \mid \text { datos })=\sum-\left[\frac{\ln \left(2 \pi \sigma_{i}^{2}\right)}{2}+\frac{(T L-\widehat{T L})^{2}}{2 \sigma_{i}^{2}}\right]
$$

For each model, the $\sigma_{i}^{2}$ was calculated using the following equations:

$$
\begin{array}{lll}
\text { VBGM: } & \sigma_{i}^{2}=\sigma_{\infty}^{2}\left[\left(1-e^{-k\left(t-t_{0}\right)}\right)\right]^{2} \\
\text { GVB: } & \sigma_{i}^{2}=\sigma_{\infty}^{2}\left[\left(1-e^{-k\left(t-t_{0}\right)}\right)^{D}\right]^{2} \\
\text { Logistic: } & \sigma_{i}^{2}=\sigma_{\infty}^{2}\left[\left(1+e^{-k\left(t-t_{1}\right)}\right)^{-1}\right]^{2} \\
\text { Gompertz: } & \sigma_{i}^{2}=\sigma_{\infty}^{2}\left[e^{\left(-e^{-k\left(t-t_{1}\right)}\right)}\right]^{2} \\
\text { Johnson: } & \sigma_{i}^{2}=\sigma_{\infty}^{2}\left[e^{-\frac{1}{k_{4}}\left(t-t_{0}\right)}\right]^{2} \\
\text { Richards } & \sigma_{i}^{2}=\sigma_{\infty}^{2}\left[\left(1+\frac{1}{A} e^{-k\left(t-t_{0}\right)}\right)^{-D}\right]^{2}
\end{array}
$$

where, $\sigma_{i}^{2}$ : is the variance for the size in age $i$ and $\sigma_{\infty}^{2}$ the variance for older organisms.

Compensatory method (Aragón-Noriega et al., 2017)

Model parameters were obtained through iterations maximizing the likelihood function of Restrepo et al. (2010) described in the previous section (depensatory method), but in this case, the $\sigma_{i}^{2}$ was calculated, with the following equations:

$$
\begin{array}{llll} 
& \text { VBGM: } & \sigma_{i}^{2} & =\sigma_{\infty}^{2}\left[\left(1-e^{-k\left(t-t_{0}\right)}\right)\right]^{-2} \\
& \text { GVB: } & \sigma_{i}^{2} & =\sigma_{\infty}^{2}\left[\left(1-e^{-k\left(t-t_{0}\right)}\right)^{D}\right]^{-2} \\
& \text { Gompertz: } & \sigma_{i}^{2} & =\sigma_{\infty}^{2}\left[e^{\left(-e^{-k(t-t 1)}\right)}\right]^{-2} \\
& \text { Johnson: } & \sigma_{i}^{2} & =\sigma_{\infty}^{2}\left[e^{-\frac{1}{k\left(t-t_{0}\right)}}\right]^{-2} \\
& \text { Logistic: } & \sigma_{i}^{2} & =\sigma_{\infty}^{2}\left[\left(1+e^{-k(t-t 1)}\right)^{-1}\right]^{-2} \\
& \text { Richards: } & \sigma_{i}^{2} & =\sigma_{\infty}^{2}\left[\left(1+\frac{1}{A} e^{-k\left(t-t_{0}\right)}\right)^{-D}\right]^{-2}
\end{array}
$$

\section{Mixed model}

The models' parameters were obtained using a mixed criterion of two non-conventional methods, which achieved better performance according to AIC. In this 
case, was maximizing the function proposed by Chen \& Fournier (1999) but with a modification in the variance: $L L(\varnothing \mid$ datos $)=\sum \ln \left\{\frac{1-p}{\sigma_{i} \sqrt{2 \pi}} e^{\left[-\frac{(T L-T L)^{2}}{2 \sigma_{i}^{2}}\right]}+\frac{2 p}{g \sigma_{i} \sqrt{\pi}}\left[1+\frac{(T L-\widehat{T L})^{4}}{\left(g \sigma_{i}\right)^{4}}\right]^{-1}\right\}$

For each model, the $\sigma_{i}^{2}$ was computed using the equations described in the depensatory section.

\section{Confidence intervals}

Confidence intervals were estimated based on likelihood profiles and chi-square distribution (Venzon \& Moolgavkar, 1988). The confidence interval was defined as all values that satisfy the following inequality:

$$
2\left(L(Y \mid \theta)-L\left(Y \mid \theta_{\text {best }}\right)\right)<\chi_{1,1-\alpha}^{2}
$$

where $L\left(Y \mid \theta_{\text {best }}\right)$ is the log-likelihood most likely value of $\theta$ and $\chi_{1,1-\alpha}^{2}$ is the value of $X^{2}$ with one degree of freedom at the confidence level of $1-\alpha$. Thus, the confidence interval at $95 \%$ of the value $\theta$ covers all values that are twice the difference between the loglikelihood of a $\theta$ given and the log-likelihood of the best estimate of a $\theta$ given one that is less than 3.84.

\section{RESULTS}

Measurements were made on 25,656 females and 12,914 males, of which 19,827 females and 10,808 males were collected inside the lagoon, whereas 5,829 females and 2,106 males were collected in the adjacent marine area. Total length (TL) intervals range from 45 to $180 \mathrm{~mm}$ for females in the lagoon and 55 to $220 \mathrm{~mm}$ in the adjacent marine zone (Fig. 2a). For males, the sizes ranged from 30 to $196 \mathrm{~mm}$ inside the lagoon and 72 to $205 \mathrm{~mm}$ in marine waters (Fig. 2b).

Two cohorts were identified in females from May to November 2002, from 77.6 to $140.9 \mathrm{~mm}$ TL and from October 2002 to January 2003, from 57.7 to $119.4 \mathrm{~mm}$ TL, inside the lagoon. A minimum of two marine cohorts was found, first one from January to May 2002 from 107 to $144.2 \mathrm{~mm}$ TL and the one from March to July 2003, from 91.8 to $143.9 \mathrm{~mm}$ TL (Fig. 3a). A cohort was identified inside the lagoon from April to June with 104.3 to $112.3 \mathrm{~mm}$ TL in males. A cohort March-July 2002 was also identified in the marine area from 95.9 to $126.7 \mathrm{~mm}$ TL (Fig. 3b).

\section{Growth curves}

In the conventional based multimodel analysis, in females, the best model was Johnson, followed by the GVB, VBGM. The best fit comes from the Johnson model with an Akaike weight of 50\%, although the GVB is also acceptable with an Akaike weight of $40 \%$. In males, only two models were represented, the
Johnson and the VBGM. The best fit was the Johnson model, with an Akaike weight of $73 \%$ (Table 1).

\section{Unconventional methods}

The classification of models with the multi-criteria strategy showed for females of Penaeus californiensis, the Johnson model as the best for all criteria, although the GVB and VBGM were also acceptable models describing growth. However, mixed criterion ("fat tail" and depensatory methods) presented the lowest AICc with 176.6 and Akaike weight of $79 \%$, followed by VBGM with AICc of 179.8 and a weight of $12 \%$. While for males, it featured the lowest AICc with 120.3 and Akaike weight of $74 \%$, the VBGM with 123.3 AICc, and a weight of $16 \%$ (Table 2).

\section{Growth curves}

The Johnson model best matched the data on the different criteria in P. californiensis. Growth curves in both females and males show the same growth pattern, except for the compensatory criterion (Fig. 4).

In the multi-criterion analysis, in both females and males of $P$. californiensis, the lowest AICc was the Johnson model, parameterized with the mixed criterion. The parameter $k=6.02(5.93-6.12)$ had significant differences with the conventional, compensatory, and "fat-tail" criteria in females. The asymptotic length was $L_{\infty}=188.8$ (186.3-191.3). It only had significant differences with the compensatory, while parameter $t_{0}$ $=0.0221 \quad(0.0207-0.0234)$ also had significant differences only with the compensatory criterion. In males' case, the growth coefficient $k=8.98$ (8.85-9.12) only presented significant differences with the compensatory criterion. The $L_{\infty}=153.3$ (151.3-155.0) did not present significant differences with any of the other criteria. While the parameter $t_{0}=0.0386(0.0378$ 0.0394), presented significant differences with the compensatory criterion. Besides, there are significant differences between the growth parameters of females and males (Table 3).

\section{DISCUSSION}

Most researchers consider penaeids growth as an ongoing process and measure size by age directly, which seems to be valid for most shrimps, where the exchange period is usually of the order of days or weeks, thus smoothing the staggered functions of individual shrimp growth over more extended periods (Dall et al., 1990).

A description of life history growth for any penaeid species has not been documented. The importance of this work lies in the description of individual growth; by gathering descriptions of the different stages of life 


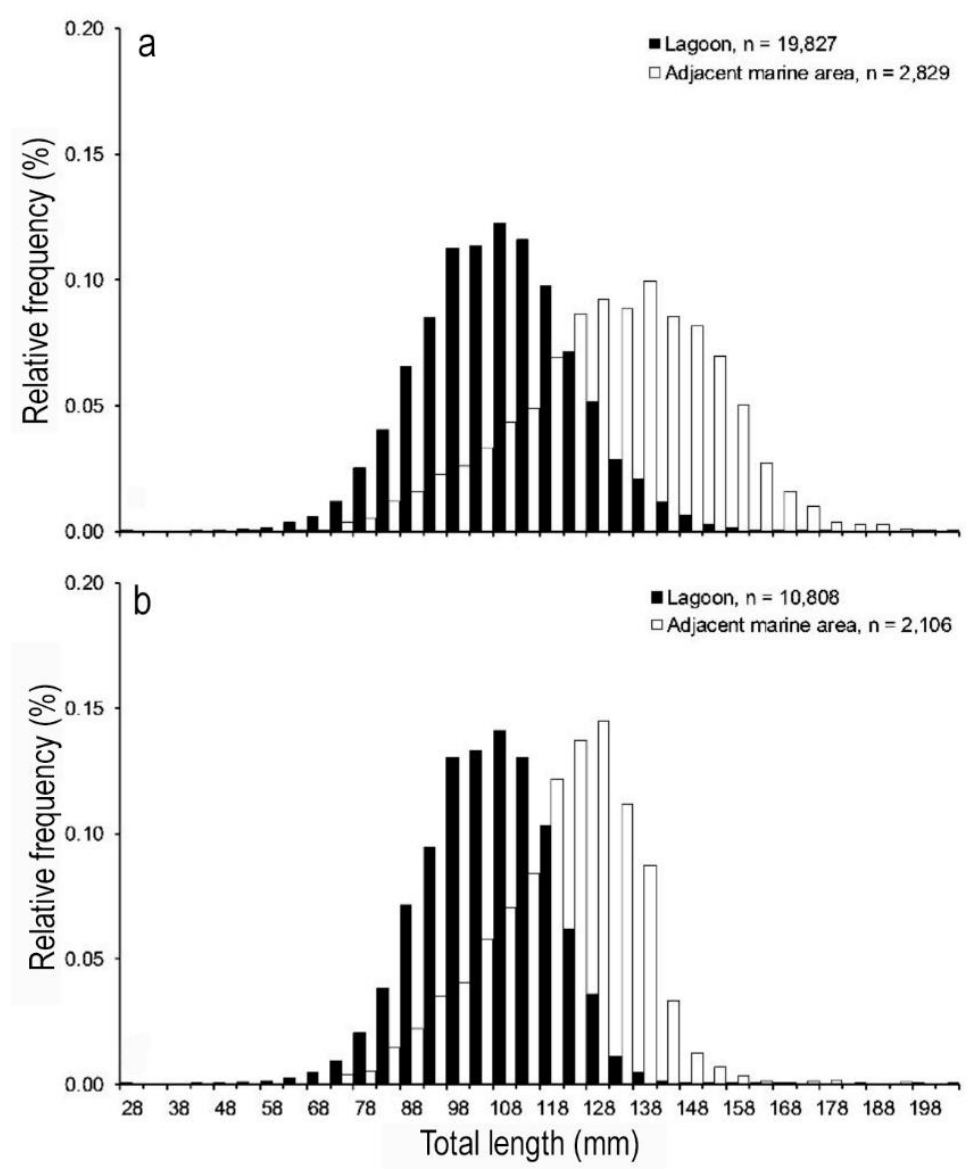

Figure 2. Size-structure of Pacific yellowlegs shrimp, Penaeus californiensis (Holmes, 1900) from samples collected in the Agiabampo coastal lagoon system and its adjacent marine zone, Sinaloa-Sonora, Mexico from January 2002 to January 2003. a) Females, b) males.

history, juveniles within the lagoon and sub-adults in the adjacent marine area, it is observed that the Penaeus californiensis follows with the typical growth pattern of crustaceans in a sigmoidal form or also called $S$ shape (Dall et al., 1990). Most growth estimates were made in the stages of life history after the tipping point. The von Bertalanffy growth model has been applied to $P$. californiensis, and growth estimates have been made for adult organisms caught by the shrimp fleet, although Chávez \& Rodríguez (1971) included the larval phase, of postlarvae and juveniles. They obtained a $k=0.1327$ and $k=0.1789$ with a monthly basis for females and males respectively, while Galicia (1976) in the same species obtained $k=0.1704$ and $k=0.1089$ also with monthly base for females and males respectively.

Montgomery et al. (2010) demonstrated that the Schnute model could describe the growth of penaeid shrimp; until that time, Schnute's growth model had not been used for a penaeid species, despite its wide acceptance in the literature on fish growth (Katsanevakis, 2006). In their study, Mongomery et al.
(2010) found that for females of Metapenaeus macleayi (from two localities in Australia), case 5 equivalent of VBGM was adjusted for males and cases 1 and 2 were adjusted for females, which are sigmoidal models.

Recent studies have used the multimodel selection approach in penaeid species. Aragón-Noriega (2016) studied the growth in cultivated Penaeus vannamei and $P$. stylirostris. He concluded that these two species' growth is sigmoid (the best-fitted model he found was Gompertz). While Monsreal et al. (2016) used Schnute's multimodel approach to juveniles and wild sub-adults of Farfantepenaeus brasiliensis and $F$. duorarum, concluded that for both species, the best describes growth is Tanaka's model (undetermined growth pattern).

Although in the review of Dall et al. (1990) mention that wild penaeid shrimp in estuaries have linear growth, and despite the results of Monsreal et al. (2016) that suggested an exponential growth, in the present study, $P$. californiensis inside the Agiabampo lagoon was best described by the Jonhson, GVB and VBGM 


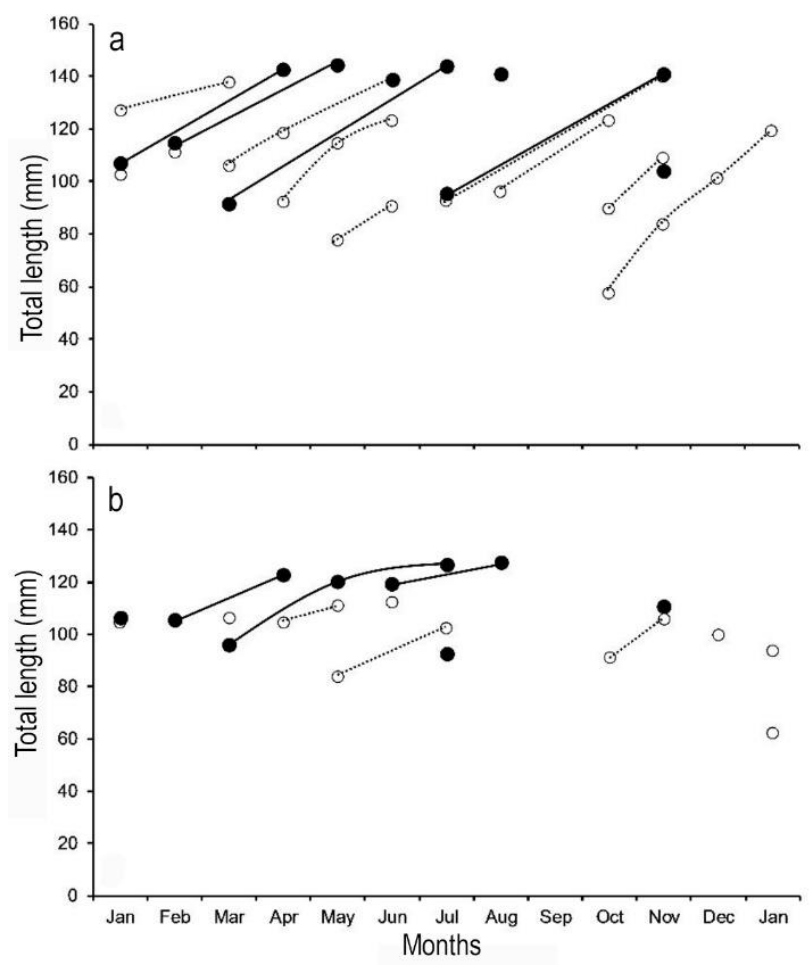

Figure 3. Modal progression of Penaeus californiensis (Holmes, 1900) from samples collected in the Agiabampo coastal lagoon system, Sinaloa-Sonora, Mexico, from January 2002 to January 2003. a) Females, b) males. Unfilled dots with a dashed line represent organisms within the coastal lagoon system; filled dots with a solid line represent organisms in the adjacent marine area.

models. Johnson's model anticipated a highly asymmetrical sigmoidal type model with the inflection point very close to zero (Ricker, 1979). GVB has a parameter to modifies the curve from sigmoidal to an inverted exponential. If sigmoidal, GVB can anticipate a curve with an inflection point for symmetrical, asymmetrical, and highly asymmetrical curves. The VBGM is an inverted exponential curve (without inflection point). So, it is no surprise that those three models were the best because their curve shape is very similar, suggesting that the shrimp population sampled in this region is above the tipping point and below the population asymptote, as mentioned in Dall et al. (1990). Therefore, it is concluded that the curve that best describes growth for juveniles and sub-adults of $P$. californiensis is sigmoidal. It is commonly accepted not to extend any growth curve out of the data analyzed, but Figure 4 shows that the sigmoid shape is not detected. For this reason, the curve described by the Johnson model was arbitrarily extended to near zero in order to observe the inflection point (Fig. 5).

On the other hand, when compared parameterized multi models with multi-criteria, we observed that the
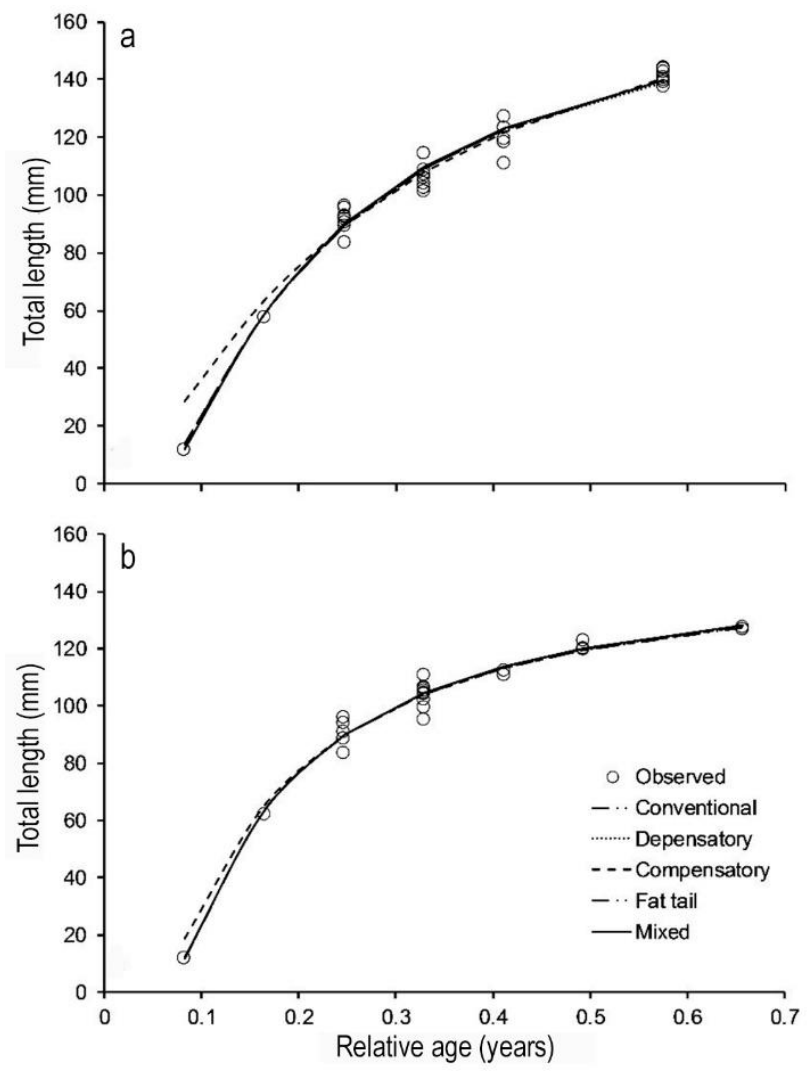

Figure 4. The Johnson model's growth curves fitted by multi-criteria, in Penaeus californiensis (Holmes, 1900) from samples collected in the Agiabampo coastal lagoon system, Sinaloa-Sonora, Mexico from January 2002 to January 2003. a) Females, b) males.

model that best fitted was Johnson for both females and males. Demonstrating the convergence of all the five criteria applied to parameterization (Tables 1-2).

Despite this finding, it is important to highlight that an objective in this study was to found a better strategy of model parameterization by the goodness of fit test of AIC. In this study, the mixture method was proposed the first time in growth literature. However, it is important to be clear that the two methods were already utilized in previous literature.

The present study's innovative approach is the mixture of both methods ("fat-tail" and depensatory). Chen \& Fournier (1999) proposed a "fat-tail" criterion, which is a combination of two or more probability distribution in which a random variable is derived from a collection of different distributions (e.g., normal distribution and a $t$-distribution). Chen \& Fournier (1999) thus proposed a two-component of combined distribution, with a probability density function of the fat-tailed distribution that required a parameter called " $g$," which was used to adjust the spread of the fat-tailed distribution. An increase in the value of $g$ tends to increase the "thickness" of the tails, thus increasing the 
Table 1. Akaike information criterion corrected $\left(A I C_{c}\right)$ and Akaike weight $\left(w_{i} \%\right)$ values for selection with the conventional method, of the best growth model for females and males of Penaeus californiensis (*best fit).

\begin{tabular}{lrrrrrrrr}
\hline \multirow{2}{*}{ Model } & \multicolumn{3}{c}{ Females } & & \multicolumn{3}{c}{ Males } \\
\cline { 2 - 5 } \cline { 6 - 8 } & $A I C_{c}$ & $\Delta_{i}$ & $w_{i}(\%)$ & & $A I C_{c}$ & $\Delta_{i}$ & $w_{i}(\%)$ \\
\hline Johnson* & 191.1 & 0.00 & $50 \%$ & & 133.7 & 0.00 & $73 \%$ \\
GVB & 191.5 & 0.45 & $40 \%$ & & 136.5 & 3.75 & $11 \%$ \\
VBGM & 194.3 & 3.20 & $10 \%$ & & 136.8 & 3.12 & $15 \%$ \\
Gompertz & 209.3 & 18.23 & $0 \%$ & & 149.4 & 15.68 & $0 \%$ \\
Richard & 214.7 & 23.68 & $0 \%$ & & 155.5 & 21.81 & $0 \%$ \\
Logistic & 220.1 & 29.04 & $0 \%$ & & 159.3 & 25.58 & $0 \%$ \\
\hline
\end{tabular}

Table 2. Akaike information criterion corrected $\left(A I C_{c}\right)$ and Akaike weight $\left(w_{i} \%\right)$ for selecting the best growth model, unconventional methods for females, and males of Penaeus californiensis (*best fit).

\begin{tabular}{llccccccc}
\hline \multirow{2}{*}{ Method } & \multirow{2}{*}{ Model } & \multicolumn{3}{c}{ Females } & & \multicolumn{3}{c}{ Males } \\
\cline { 3 - 5 } \cline { 7 - 9 } & & $A I C_{c}$ & $\Delta_{i}$ & $w_{i}(\%)$ & & $A I C_{c}$ & $\Delta_{i}$ & $w_{i}(\%)$ \\
\hline \multirow{5}{*}{ Fat tail } & Johnson* & 182.1 & 0.00 & 52 & & 126.4 & 0.00 & 73 \\
& GVB & 182.8 & 0.71 & 37 & & 129.9 & 3.49 & 13 \\
& VBGM & 185.3 & 3.22 & 10 & & 129.6 & 3.22 & 15 \\
& Gompertz & 200.1 & 17.99 & 0 & & 143.0 & 16.62 & 0 \\
& Johnson* & 190.5 & 0.00 & 77 & & 134.5 & 0.00 & 72 \\
& VBGM & 194.1 & 3.60 & 13 & & 137.0 & 2.55 & 20 \\
& GVB & 194.5 & 4.01 & 10 & & 138.8 & 4.30 & 8 \\
\multirow{5}{*}{ Mixed* } & Gompertz & 221.4 & 30.81 & 0 & & 157.6 & 23.08 & 0 \\
& Johnson* & 194.7 & 0.00 & 47 & & 139.0 & 0.00 & 57 \\
& VBGM & 195.9 & 1.17 & 26 & & 140.2 & 1.25 & 31 \\
& GVB & 195.9 & 1.18 & 26 & & 142.5 & 3.48 & 10 \\
& Gompertz & 201.4 & 6.66 & 2 & & 145.3 & 6.29 & 2 \\
& Johnson* & 176.0 & 0.00 & 79 & & 120.3 & 0.00 & 74 \\
& VBGM & 179.8 & 3.81 & 12 & & 123.3 & 3.01 & 16 \\
& GVB & 180.3 & 4.35 & 9 & & 124.5 & 4.16 & 9 \\
& Gompertz & 208.6 & 32.62 & 0 & & 145.8 & 25.45 & 0 \\
\hline
\end{tabular}

probability of having extreme values that are far away from the mean value. For the proposed two-component mixture distribution, they also required a parameter " $p$ " that represents the "problem" observations (outliers). Despite the novel of the proposed method by Chen \& Fournier (1999), it has a concern; it works with constant variance. Individual variability-at-age is real and irrefutable; in effect, it has been considered and formulated since Schnute \& Fournier (1980) it has been proposed in two ways: "growth compensation" (individual variability tends to decrease with age) and "growth depensation" (individual variability tends to increase with age). Schnute \& Fournier (1980) expressed with these words, "it may happen that younger fish experience considerable variability in growth rate, while older fish tend to reach limiting size." This peculiarity was called "growth compensation" (AragónNoriega et al., 2017). However, Schnute \& Fournier (1980) also mentioned that "many factors may contribute to size variation among fish of one age." It is also possible that individual variability tends to increase with age. This expression was first time evaluated by Restrepo et al. (2010), and later by Luquin-Covarrubias et al. (2016), they named this type of individual variability "growth depensation." However, Restrepo et al. (2010) just solved the problems using the wellknown and very widely used Von Bertalanffy growth model. Luquin-Covarrubias et al. (2016) prolonged the analysis to six asymptotic models. The first time, Restrepo et al. (2010) developed an equation to solve the growth depensation issue, and Luquin-Covarrubias et al. (2016) developed the equations for the other five models. On the other hand, Aragón-Noriega et al. (2017) also developed the equations to compute the growth compensation in five asymptotic models.

The innovation proposed in the present study is the use of Chen \& Fournier's (1999) equation, but instead of using the constant variance, the depensatory equa- 
Table 3. Parameters and confidence intervals for the Johnson multi-criteria, for females and males of Penaeus californiensis (a significant lower than b and c; b significant lower than $\mathrm{c}$ but higher than $\mathrm{a} ; \mathrm{c}$ the highest value. Numbers with same letter are not significant different).

\begin{tabular}{llccc}
\hline Sex & Method & $k$ & $L_{\infty}$ & $t_{0}$ \\
\hline Females & Conventional & $5.67^{\mathrm{b}}$ & $191.3^{\mathrm{a}}$ & $0.0149^{\mathrm{b}}$ \\
& & $(5.53-5.82)$ & $(188.8-193.9)$ & $(0.0082-0.0215)$ \\
& Fat tail & $5.70^{\mathrm{b}}$ & $191.4^{\mathrm{a}}$ & $0.0159^{\mathrm{b}}$ \\
& & $(5.56-5.85)$ & $(188.8-193.9)$ & $(0.0094-0.0224)$ \\
& Depensatory & $6.10^{\mathrm{c}}$ & $186.9^{\mathrm{a}}$ & $0.0226^{\mathrm{b}}$ \\
& & $(5.99-6.21)$ & $(184.4-189.4)$ & $(0.021-0.0241)$ \\
& Compensatory & $4.12^{\mathrm{a}}$ & $208.7^{\mathrm{b}}$ & $-0.0396^{\mathrm{a}}$ \\
& & $(4.04-4.20)$ & $(206.3-211.1)$ & $(-0.0477-0.0315)$ \\
& Mixed & $6.02^{\mathrm{c}}$ & $188.8^{\mathrm{a}}$ & $0.0221^{\mathrm{b}}$ \\
& & $(5.93-6.12)$ & $(186.3-191.3)$ & $(0.0207-0.0234)$ \\
& Conventional & $9.19^{\mathrm{b}}$ & $152.1^{\mathrm{a}}$ & $0.0398^{\mathrm{b}}$ \\
& & $(8.87-9.52)$ & $(150.1-154.1)$ & $(0.0335-0.0461)$ \\
& Fat tail & $9.23^{\mathrm{b}}$ & $152.0^{\mathrm{a}}$ & $0.0400^{\mathrm{b}}$ \\
& & $(8.91-9.56)$ & $(150.1-154.0)$ & $(0.0341-0.0461)$ \\
& Depensatory & $9.09^{\mathrm{b}}$ & $152.5^{\mathrm{a}}$ & $0.0391^{\mathrm{b}}$ \\
& & $(8.92-9.28)$ & $(150.5-154.6)$ & $(0.0379-0.0401)$ \\
& Compensatory & $8.36^{\mathrm{a}}$ & $154.5^{\mathrm{a}}$ & $0.0253^{\mathrm{a}}$ \\
& & $(8.08-8.64)$ & $(152.7-156.3)$ & $(0.0166-0.0340)$ \\
& Mixed & $8.98^{\mathrm{b}}$ & $153.3^{\mathrm{a}}$ & $0.0386^{\mathrm{b}}$ \\
& & $(8.85-9.12)$ & $(151.7-155.0)$ & $(0.0378-0.0394)$ \\
\hline
\end{tabular}

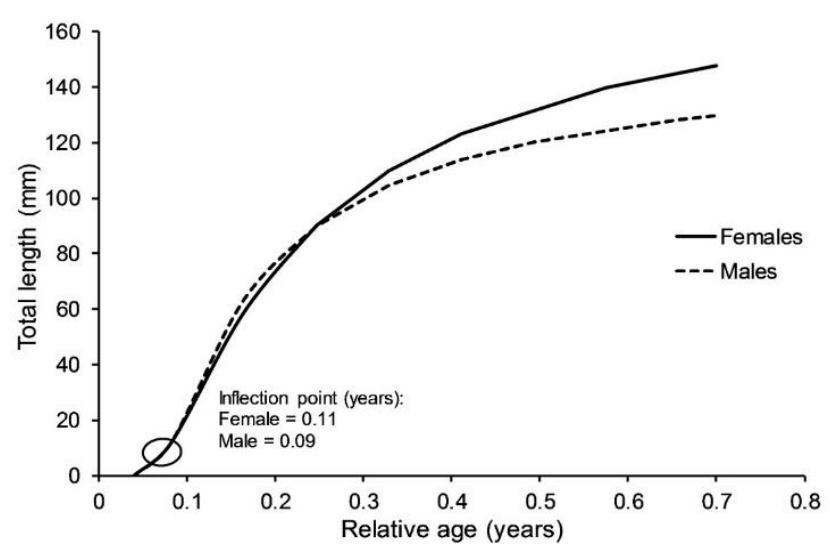

Figure 5. The Johnson model's growth curves fitted by a mixed criterion ("fat-tail" and depensatory), in females and males of Penaeus californiensis (Holmes, 1900) from samples collected in the Agiabampo coastal lagoon system, Sinaloa-Sonora, Mexico during January 2002 to January 2003.

tions for each model were applied. It is important to mention that in this study, the equations for depensatory variance was used because the AIC values were lower than equations for compensatory variance. However, they can be used in other studies if compensatory variance is observed in a particular species under study.

A new challenge in selecting models is to consider the variability-at-age. Computing values of $\sigma^{2}$ through optimization of $\sigma_{\infty}^{2}$ led to the best interpretation of length-at-age; this cannot be observed if the variance is assumed as constant (conventional method or fat tail approach). In the present study, the wide variability of length-at-age for the older individual was demonstrated by the AIC value. The mixed objective function constructed in the present study had the advantages to demonstrate intrinsic variability of length-at-age that cannot be observed if the objective function is solved (as traditionally occurs) based on the conventional or fat tail approach.

\section{CONCLUSIONS}

In conclusion: 1) the approach found in this study as best (a mixture of the "fat-tail" and growth depensation) leads to the application of a very high-performance objective function to analyze individual length-at-age variability; 2) leads to parametrize the models with strong support, and 3) shows that the best model to describe the growth trajectory of Penaeus californiensis in marine and estuarine environments is a sigmoid curve with an inflection point near to cero age (Johnson model).

\section{ACKNOWLEDGMENTS}

JAFO thanks the National Council of Science and Technology (CONACYT) for the scholarship awarded 
to complete its postgraduate studies (grant number 86811). Edgar Alcántara Razo of the CIBNOR Applied Fisheries Ecology Laboratory for his support in improving figures.

\section{REFERENCES}

Akaike, H. 1973. Information theory and an extension of the maximum likelihood principle. In: Petrov, B.N. \& Csaki, F. (Eds.). 2nd International Symposium on Information Theory: 268281. Akademiai Kiado, Budapest, pp. 267-281.

Aragón-Noriega, E.A. 2016. Crecimiento individual de camarón blanco Litopenaeus vannamei (Boone, 1931) y camarón azul Litopenaeus stylirostris (Stimpson, 1874) (Decapoda: Penaeidae) con un enfoque multimodelo. Latin American Journal of Aquatic Research, 44(3): 480-486. doi: 10.3856/vol44-issue3-fulltext-6

Aragón-Noriega, E.A. \& Calderón-Aguilera, L.E. 2001. Age and growth of shrimp postlarvae in the upper Gulf of California. Journal of Ichthyology and Aquatic Biology, 4(3): 99-104.

Aragón-Noriega, E.A., Mendivil-Mendoza, J.E., AlcántaraRazo, E., Valenzuela-Quiñonez, W. \& Félix-Ortiz, J.A. 2017. Multi-criteria approach to estimate growth curve in the marine shrimp Penaeus vannamei, (Decapoda: Penaeidae). Crustaceana, 90(11-12): 1513-1531. doi: 10.1163/15685403-00003729

Burnham, K.P. \& Anderson, D.R. 2002. Model selection and multimodel inference: a practical informationtheoric approach. Springer, New York.

Chávez, E.A. \& Rodríguez, M.C. 1971. Estudio sobre el crecimiento del camarón café (Penaeus californiensis Holmes). Revista de la Sociedad Mexicana de Historia Natural, 32: 111-127.

Chen, Y. \& Fournier, D. 1999. Impacts of atypical data on Bayesian inference and robust Bayesian approach in fisheries. Canadian Journal of Fisheries and Aquatic Sciences, 56: 1525-1533.

Dall, W., Hill, B.J., Rothlisberg, P.C. \& Staples, D.J. 1990. The biology of the Penaeidae. In: Blaxter, J.H.S. \& Southward, A.J. (Eds.). Advances in marine biology. Academic Press, London.

Galicia, X.R. 1976. Crecimiento del camarón azul, Penaeus stylirostris, y camarón café, Penaeus californiensis, en la zona de Puerto Peñasco, Sonora. In: Castro-Aguirre, J.L. (Ed.). Memorias, simposio sobre biología y dinámica poblacional de camarones. Instituto Nacional de Pesca, Ciudad de México, pp. 189-211.

Gompertz, B. 1825. On the nature of the function expressive of the law of human mortality and on a new model of determining life contingencies. Philosophical Transactions of the Royal Society, 115: 513-585.

Haddon, M. 2001. Modelling and quantitative methods in fisheries. Chapman and Hall/CRC Press, Boca Raton.

Hilborn, R. \& Walters, C. 1992. Quantitative fisheries stock assessment: choice, dynamics and uncertainty. Chapman \& Hall, New York.

Johnson, N.O. 1935. A trend line for growth series. Journal of American Statistical Association, 30(192): 717. doi: 10.1080/01621459.1935.10503297

Katsanevakis, S. 2006. Modelling fish growth: model selection, multimodel inference and model selection uncertainty. Fisheries Research, 81: 229-235. doi: 10.1016/j.fishres.2006.07.002

Krüger, F. 1969. Das asymptotische wachstum der fischeein nonsens? Helgolander Wiss Meeresunters, 19: 205215.

López, J, Arreguín, F., Hernández, S., García, A.R. \& Valenzuela, W. 2003. Inter-annual variation of growth of the brown shrimp Farfantepenaeus californiensis and its relation to temperature. Fisheries Research, 61: 95-105.

Luquin-Covarrubias, M.A, Morales, E., González, S.S. \& Lluch, D.B. 2016. Joint likelihood function based on multinomial and normal distributions for analyzing the phenotypic growth variability of geoduck clam Panopea globosa. CalCOFI Reports, 57: 151-162.

MacDonald, P.D.M. \& Pitcher, T.J. 1979. Age groups from size-frequency data: a versatile and efficient method of analyzing distribution mixtures. Journal of the Fisheries Research Board of Canada, 36: 987-1001.

Monsreal, K., Velázquez, I. \& Poot, G.R. 2016. Model selection for determining the growth of juveniles and sub-adults of two species of shrimp (Decapoda, Penaeidae) in a tropical coastal lagoon. Crustaceana, 89(1): 29-45. doi: 10.1163/15685403-00003510

Montgomery, S.S., Walsh, C.T., Haddon, M., Kesby C.L. \& Johnson, D.D. 2010. Using length data in the Schnute Model to describe growth in a metapenaeid from waters off Australia. Marine and Freshwater Research, 61: 1435-1445.

Ortega, G.G., Rodríguez, G., Pérez, R., Castañeda, N. \& Aragón, E.A. 2016. Estimation of growth parameters of male blue crabs Callinectes arcuatus (Brachyura: Portunidae) from the Gulf of California using the Schnute model. Latin American Journal of Aquatic Research, 44(2): 371-379. doi: 10.3856/vol44-issue2fulltext-18

Restrepo, V.R., Diaz, G.A., Walter, J.F., Neilson, J.D., Campana, S.E., Secor, D. \& Wingate, R.L. 2010. Updated estimate of the growth curve of Western Atlantic bluefin tuna. Aquatic and Living Resources, 23: 335-342. doi: 10.1051/alr/2011004 
Richards, F.J. 1959. A flexible growth function for empirical use. Journal of Experimental Botany, 10(2): 290-301. doi: 10.1093/JXB/10.2.290

Ricker, W.E. 1975. Computation and interpretation of biological statistics of fish populations. Bulletin of the Fisheries Research Board of Canada, 191: 1-382.

Ricker, W.E. 1979. Growth rates and models. In: Hoar, W.S., Randall, D.J. \& Brett, J.R. (Eds.). Fish physiology. Bioenergetics and growth. Academic Press, London, pp. 677-744.

Rivera-Velázquez, R., Salgado-Ugarte, I., Soto, L. \& Naranjo, E. 2010. Un estudio de caso en el análisis de la distribución de frecuencias de tallas de Litopenaeus vannamei (Boone, 1931) mediante el uso de estimadores de densidad por Kernel. Latin American Journal of Aquatic Research, 38(2): 201-209. doi: 10.3856/vol38-issue2-fulltext-4

Rodríguez-Domínguez, G., Castillo-Vargasmachuca, S., Pérez-González, R. \& Aragón-Noriega, E.A. 2012. Estimation of the individual growth parameters of the brown crab Callinectes bellicosus (Brachyura, Portunidae) using a multi-model approach. Crustaceana, 85(1): 55-69.

Schnute, J. 1981. A versatile growth model with statistically stable parameters. Canadian Journal of Fisheries and Aquatic Sciences, 38: 1128-1140.

Schnute, J. \& Fournier, D. 1980. A new approach to length-frequency analysis: growth structure. Canadian Journal of Fisheries and Aquatic Sciences, 37: 13371351.

Received: 7 February 2020; Accepted: 2 July 2020
Sparre, P. \& Venema, S.C. 1998. Introducción a la evaluación de recursos pesqueros tropicales. Parte 1. Manual. FAO Documento Técnico de Pesca, FAO, Rome.

Valenzuela, W., Aragón, E.A., Arréola, J.A., Salinas, C.A., Lluch, S.E. \& Hernández, S. 2006. Habitat use for growth and recruitment of the Pacific yellow leg shrimp, Farfantepenaeus californiensis (Decapoda, Penaeidae) on the continental shelf and adjacent Laguna Agiabampo, Mexico. Crustaceana, 79: 933948.

Venzon, D.J. \& Moolgavkar, S.H. 1988. A method for computing profile-likelihood-based confidence intervals. Applied Statistics, 37(1): 87-94.

Vogt, G. 2012. Ageing and longevity in the Decapoda (Crustacea): a review. Zoologischer Anzeiger, 251: 125.

Von Bertalanffy, L. 1938. A quantitative theory of organic growth (inquiries on growth laws II). Human Biology, 10: $181-213$.

Zhu, L., Li, L. \& Liang, Z. 2009. Comparison of six statistical approaches in the selection of appropriate fish growth models. Chinese Journal of Oceanology and Limnology, 27: 457-467. doi: 10.1007/s00343009-9236-6 